\title{
Criminalización de la protesta social
}

\author{
Aportes Andinos \\ Revista electrónica de derechos humanos \\ Programa Andino de Derechos Humanos (PADH) \\ Universidad Andina Simón Bolívar, Sede Ecuador \\ No. 30, Criminalización de la protesta social y derechos humanos \\ Tema Central \\ Abril 2012
}

\section{Jacobo Silva Nogales México}

\section{Marco conceptual}

Prácticamente cualquiera conoce ya de la existencia de la criminalización de la protesta social, puesto que se ha convertido en un lugar común, y aunque quizá no entendamos exactamente lo mismo por ese concepto, no dudamos que la hay, sobre todo cuando la estamos viviendo cotidianamente.

Llegado a ese punto lo que hace falta es un marco conceptual dentro del cual pueda ubicarse adecuadamente, ubicación que es importante en dos sentidos: en primer lugar por su interés teórico, que parte del mero interés intelectual y contribuye a definirla mejor cada vez; en segundo lugar, por el interés práctico que tiene para los luchadores sociales, interés que se deriva de que en la situación actual ser lo que son es estar a un paso de ser fotografiados de frente y de perfil vistiendo un uniforme beige, con un letrero en el pecho y teniendo que hacer sentadillas desnudos diez veces al día.

Establezcamos pues ese marco conceptual, y para ello ayudémonos con un servicio similar al que se encuentra en Internet y que sirve para ubicarse geográficamente cuando no se sabe donde se encuentra uno o cuando quiere llegarse a un destino determinado. Si éste se Ilama Google Earth, Ilamémosle Google Concept a aquel que nos ubicará conceptualmente, el cual acabamos de inventar. Lo conceptual es porque existe solamente en el concepto y porque para encontrar conceptos nos ha de servir.

Entramos al programa con un simple click y con otros más encontraremos el concepto que buscamos. El primer doble click nos ayuda a mirar que en esta universidad se acusó y condenó como si fueran criminales a unos luchadores sociales. Ese marco nos permite decir que existe un caso de criminalización de luchadores sociales.

El segundo, al alejarnos un poco, nos permite saber que ese que antes vimos no es el único caso porque hay otros más, lo que quiere decir que se está criminalizando a todo tipo de luchadores sociales, algunos de ellos participantes en luchas electorales inclusive. Ese marco nos permite afirmar que hay una Criminalización de la Protesta Social.

El tercero, al alejarnos un poco más, nos deja ver ocho mil cámaras en la Ciudad de México, policías por todas partes, abusos de todo tipo contra la población, detención de personas inocentes con fines de investigación, pero que son tratadas desde un principio como si fueran culpables. Eso quiere decir que no solamente los movimientos opositores son víctimas de la criminalización sino que la población en general está criminalizada. Esto porque los 
gobiernos que no son representativos de la población, como es el caso del gobierno mexicano, consideran a ésta su enemiga y así ha ocurrido desde hace muchos años en el país, pero ahora, al estimarla cada vez más completamente como oposición real o potencial, el gobierno mexicano la considera abiertamente como formada por criminales, y ese es el trato que le otorga, a tal grado que pareciera que se tratara de un gobierno de ocupación. Ese marco permite asegurar que hay una Criminalización de la Población.

El cuarto, al alejarnos todavía más nos hace ver que lo mismo ocurre en distintos países de América y en otros continentes. ¿Qué quiere decir esto? Que estamos ante una política general dependiente de algún centro desde el que se pretende gobernar el mundo. Desde ahí, desde muy arriba se puede ver esa política o estrategia general del imperio y saber que se Ilama Estrategia de Dominio de Espectro Completo que se compone de varias fases: prevención, disuasión, persecución y aniquilamiento, y que la criminalización de la protesta social forma parte de las dos primeras de esas cuatro fases, que son las más importantes de todas, es decir de la prevención y de la disuasión, con las que pretende inhibir el surgimiento de una fuerza opositora con posibilidades de realizar un cambio social. Ese nuevo marco nos permite conocer esa Estrategia de Dominio de Espectro Completo.

El quinto, con la vista desde más lejos todavía, nos ayuda a mirar que el gobierno norteamericano está en guerra contra todo el mundo, que así lo considera, y que para enfrentar esa guerra total aplica una forma de guerra denominada Guerra Asimétrica o Guerra de Cuarta Generación, con la que asume que está en libertad de utilizar medios ilegales contra sus adversarios y que debe hacerse pasar por víctima ante la comunidad internacional y su pueblo. A esa estrategia obedece la creación de las cárceles negras como la de Guantánamo y hechos como los de Abu Grahib o la legalización de la tortura. Ese marco nos permite enterarnos de la Guerra Asimétrica.

El sexto, la vista más lejana que el programa permite, deja ver algo más: que esa guerra asimétrica es una forma particular de las Guerras de Cuarta Generación, lo que quiere decir que antes hay otras tres tipos o generaciones de guerra, cada una con sus peculiaridades: la primera generación basada en el enfrentamiento de masas de hombres, con táctica de líneas y columnas; la segunda generación basada en el uso de una gran potencia de fuego, en particular de artillería; la tercera generación basada en la velocidad y la sorpresa; la cuarta generación basada en el terrorismo, en la labor de inteligencia, en la guerra psicológica y mediática y en las operaciones irregulares. Ese marco, el más grande de todos nos permite conocer de las Guerras de Cuarta Generación.

Así, después de varios clicks, podemos decir, recapitulando todo lo anterior, que la criminalización de la protesta social es una medida contrainsurgente que forma parte de las fases preventiva y disuasiva de la Estrategia de Dominio de Espectro Completo que el imperio desarrolla dentro de la Guerra Asimétrica que realiza en algunas regiones del mundo, y que ésta es una de las formas en que se expresan las Guerras de Cuarta Generación.

Ahora, con la ventaja de esa visión ampliada que permite ubicar el marco conceptual de la criminalización de la protesta social podemos ampliar nuestra comprensión de ella para ver que es solamente uno de las componentes de la Estrategia de Dominio de Espectro Completo y entender como parte de ésta a muchos otros fenómenos que pueden observarse en la situación actual de nuestro país.

También nos permite comprender las razones de que el Estado ubique en la categoría de delitos conductas propias de la lucha social, como ocurre con el secuestro equiparado, figura bajo la cual se acusa y condena a luchadores sociales que retienen funcionarios o personas. Igual sucede con sedición, delito del que se acusa y se puede acusar a cualquiera que participa en confrontaciones con fuerzas policiacas, como se hizo con Flavio Sosa. Lo mismo ocurre con sabotaje, delito del que se puede acusar al que con un plantón obstruya el funcionamiento de alguna vía de comunicación o de alguna empresa estatal, o con el delito 
de conspiración del que se puede culpar al que acuerde con otros cometer cualquiera de las conductas mencionadas.

A manera de ejemplo podemos mencionar que represiones brutales como la de Atenco, Oaxaca o la de Aguas Blancas o Acteal están unidas por un hilo conductor entre ellas y con otros fenómenos como la desaparición de varios luchadores sociales o los aparentemente no políticos asesinatos de Beltrán Leyva y varios otros narcotraficantes de algunas bandas por parte del ejército mexicano, así como con la acusación por delitos emparentados con delitos comunes a Flavio Sosa y los integrantes de la APPO y a Nacho del Valle y los presos de Atenco y de francos delitos comunes al profesor Máximo Mojica de Guerrero, o con las ofertas de comprar la tierra, ahora con precios altos, a los habitantes de Atenco y pueblos vecinos.

¿Cuál es el hilo conductor de estos fenómenos tan disímiles? Que todos forman parte de la formación de falsos sentidos comunes y de un nuevo imaginario creado desde el poder, ambos con el objetivo de garantizar el dominio del imperio.

Lo primero, es decir los actos represivos brutales, como actos intencionalmente encaminados a crear el sentimiento de impotencia; lo segundo, es decir, el clima del miedo y la utilización del miedo como arma política, orientados a fomentar la sensación de inseguridad; lo tercero, es decir, la descalificación de los luchadores sociales como delincuentes comunes, dirigido a provocar su aislamiento y su correspondiente sensación respecto de la población y la desesperanza; y el cuarto aderezado a fomentar la competencia entre la población. Todo encaminado a romper los lazos sociales comunitarios, el tejido social que sostiene las luchas de resistencia del pueblo y de esa manera inhibir el desarrollo de movimientos sociales con posibilidades de convertirse en alternativas viables. Todo ello como parte esencial de la prevención y disuasión de la Estrategia de Dominio de Espectro Completo, con las que pretende disminuir el riesgo del surgimiento de una fuerza capaz de poner en entredicho su dominio y ahorrarse el esfuerzo que presupondría después su persecución y su aniquilamiento.

Esos eventos se unen a su vez a otros como la atención redirigida hacia algunas regiones del mundo en que los países desarrollados parecían haber perdido interés, como África o algunos lugares de Asia, por la dependencia que tienen respecto de alguna materia prima necesaria para la tecnología de punta, o los estudios acelerados de todo el subsuelo del planeta, o el desarrollo y la aplicación de tecnología de la vigilancia cada vez más sofisticada o la presencia de militares norteamericanos en Haití, o el golpe de Estado en honduras o la acrecentada labor de inteligencia en todo el mundo. Pero ¿qué es lo que une esto con lo anteriormente señalado? Que todo va encaminado a ejercer un domino del mundo por tierra, agua, aire, subsuelo y espacio, lo que es el objetivo de la estrategia de dominio de espectro completo.

Así las cosas, esa vista ampliada nos permite observar el lugar que ocupa algo que podría parecer un fenómeno aislado que no lo es en absoluto sino que forma parte de un conjunto de hechos coherentemente unidos en una estrategia global contrainsurgente.

\section{2. ¿Qué hacer ante este fenómeno?}

Pasemos ahora a la otra parte que nos interesa, no ya por mero interés intelectual sino como asunto vital: ¿qué debemos hacer en como luchadores sociales ante esta situación?

Desgraciadamente nada es perfecto y el programa de Google Concept alguna falla debía tener: no está hecho para hallar soluciones, así que tenemos que confiar en algo más tradicional: el sentido común,

¿Pero cuál sentido común? El nuevo sentido común de impotencia, generado por la 
Estrategia de Dominio de Espectro Completo, si lo hemos hecho nuestro nos aconsejaría no meternos en problemas y nos haría alejarnos lo más posible de las situaciones que nos puedan involucrar más todavía en la lucha social, lo que implicaría someternos completamente a los designios de los poderosos de México y el mundo.

El otro sentido común, el viejo, el de los que resisten a esa estrategia y que va ligado a los intereses comunitarios y se encuentra en pugna con el nuevo y que se niega a morir, nos aconseja, por el contrario, persistir en la lucha, resistir, en el entendido de que si no lo hacemos terminaremos siendo los mexicanos una sociedad atemorizada como nunca, individualista como pocas, totalmente dominada, en la que a nadie le importará lo que a otro le suceda.

Ante esa brutalidad podemos impactarnos como lo busca la doctrina del shock que tan bien trata Naomi Klein en su obra y que forma parte de la fase preventiva de la estrategia norteamericana y quejarnos luego de lo que ocurrió, ya arrepentidos de lo que la inconsciencia nos movió a realizar, o podemos asumir el costo de lo que suceda, sabiendo que vale la pena defenderse, como lo hacen Nacho del Valle y Felipe Álvarez en particular, que son los casos que conozco de gente que dice: iy si hace falta nos pudrimos en la cárcel, pero no nos rajamos: la tierra no se vende!

Podemos ser indiferentes a la injusticia o seguirnos indignando y haciendo algo para evitarlo.

Podemos inmovilizarnos o crear nuestra propia estrategia, con su respectiva fase preventiva que nos haga estar listos para enfrentar en mejores condiciones lo que se nos viene encima. Eso requeriría fortalecer esos lazos comunitarios que desean destruir nuestros adversarios, crear nuevos, apoyarnos entre nosotros y afianzar nuestros lazos con la población

Podemos seguir viejos moldes, actuando como si estuviéramos aún en el siglo pasado, o peor aún, en el antepasado, guiándonos por estrategias que alguien formuló hace más de cien años, tomándolas como fórmulas infalibles, pero podemos también estar al día en lo que ocurra, explorando las nuevas situaciones que deben enfrentarse, las necesidades que nos plantean, y las nuevas posibilidades que ante nosotros se nos abren, porque por más novedosa que un arma sea, siempre hay un escudo contra ella.

Podemos aventurarnos por ese terreno que nunca puede ser suficientemente explorado porque cambia constantemente y muestra nuevas facetas cada vez Actuar así sería hacer lo que hicieron en su tiempo los que crearon una estrategia revolucionaria que les funcionó: extrayendo de la realidad su propio camino, no de los libros solamente. Eso es de sentido común, pero del bueno. Y funciona.

El camino está abierto para quien quiera transitarlo.

[1] Artículo reproducido del blog de
‘http://jacobosilvanog.blogspot.com/2010/02/criminalizacion-de-la-protesta-social.html..

\footnotetext{
Programa Andino de Derechos Humanos, PADH

Toledo N22-80, Edif. Mariscal Sucre, piso 2

Apartado Postal: 17-12-569 • Quito, Ecuador

Teléfono: (593 2) 3227718 • Fax: (593 2) 3228426

Correo electrónico: padh@uasb.edu.ec
} 